\title{
Methodological advances
}

\author{
J.-D. Lebreton \& K. H. Pollock
}

Lebreton, J.-D. \& Pollock, K. H., 2004. Methodological advances. Animal Biodiversity and Conservation, 27.1: $147-148$.

The study of population dynamics has long depended on methodological progress. Among many striking examples, continuous time models for populations structured in age (Sharpe \& Lotka, 1911) were made possible by progress in the mathematics of integral equations. Therefore the relationship between population ecology and mathematical and statistical modelling in the broad sense raises a challenge in interdisciplinary research. After the impetus given in particular by Seber (1982), the regular biennial EURING conferences became a major vehicle to achieve this goal. It is thus not surprising that EURING 2003 included a session entitled "Methodological advances". Even if at risk of heterogeneity in the topics covered and of overlap with other sessions, such a session was a logical way of ensuring that recent and exciting new developments were made available for discussion, further development by biometricians and use by population biologists.

The topics covered included several to which full sessions were devoted at EURING 2000 (Anderson, 2001) such as: individual covariates, Bayesian methods, and multi-state models. Some other topics (heterogeneity models, exploited populations and integrated modelling) had been addressed by contributed talks or posters. Their presence among "methodological advances", as well as in other sessions of EURING 2003, was intended as a response to their rapid development and potential relevance to biological questions. We briefly review all talks here, including those not published in the proceedings.

In the plenary talk, Pradel et al. (in prep.) developed GOF tests for multi-state models. Until recently, the only goodness-of-fit procedures for multistate models were ad hoc, and non optimal, involving use of standard tests for single state models (Lebreton \& Pradel, 2002). Pradel et al. (2003) proposed a general approach based in particular on mixtures of multinomial distributions. Pradel et al. (in prep.) showed how to decompose tests into interpretable components as proposed by Pollock et al. (1985) for the CormackJolly-Seber model

Pledger et al. (in prep.) went on in their thorough exploration of models with heterogeneity of capture (Pledger \& Schwarz, 2002; Pledger et al., 2003), by considering the use of finite mixture models for the robust design. Given the level of details in demographic traits presently addressed by capture-recapture, the problem of heterogeneity, once apparently settled by fairly reassuring messages (Carothers, 1973, 1979), is becoming again a central issue, with potential disastrous consequences if improperly handled. Heterogeneity models, that bear also a relationship to "multi-event models" (Pradel, in press), will thus certainly be increasingly useful. Pollock, Norris, and Pledger (in prep.) reviewed the capture-recapture models as applied to community data (Boulinier et al., 1998) and developed general removal and capturerecapture models when multiple species are sampled to estimate community parameters. Because of unequal delectability between species, these approaches bear a clear relationship to heterogeneity models, which will be more and more a reference for comparative studies of communities and "macroecology" (Gaston \& Blackburn, 2000).

Jean-Dominique Lebreton, CEFE / CNRS, 1919 Route de Mende, 34293 Montpellier cedex 5, France. E-mail: lebreton@cefe.cnrs-mop.fr Kenneth H. Pollock, Zoology, Biomathematics and Statistics, North Carolina State Univ., Box 7617, Raleigh NC 27695-7617, U.S.A. E-mail: pollock@unity.ncsu.edu 
Bonner \& Schwarz (2004) proposed a capture-recapture model with continuous individual covariates changing over time more fully developed in Bonner \& Schwarz (2004). The difficulty here is to set up a submodel predicting the covariate value when an individual is not captured. While multi-state models permit an ad hoc treatment by categorizing the covariate, Bonner and Schwarz bring a sound answer by considering the covariate obeys a Markov chain with continuous state-space.

Otis \& White (2004) presented a thorough, simulation-based, investigation of two approaches used to test the contrasting hypotheses of additive and compensatory hunting mortality based on band recovery data. The two approaches are the usual ultra-structural model and a new one based on a random effects model. This paper can be viewed as part of a revival of studies of the dynamics of exploited populations, in the broad sense, including the study of man-induced mortality in the framework of conservation biology (Lebreton, in press). This revival is a direct consequence of the increasing impact of man on the biosphere and of continuing methodological progress (Ferson \& Burgman, 2000). The use of random effects models (see also Schaub \& Lebreton, 2004) directly builds upon the seminal work by Anderson and Burnham (1976).

Stauffer presented a Winbugs implementation of the Cormack-Jolly-Seber model that complemented other presentations in the conference and the short course. Finally, Morgan, Besbeas, Thomas, Buckland, Harwood, Duck and Pomery, proposed a thorough and timely review of integrated modelling, i.e., in our context, of models considering simultaneously capture-recapture demographic information and census information. These methods were covered in other sessions, in relation to Bayesian methodology. Integrated modelling appears indeed to be the logical way of combining all pieces of information arising from integrated monitoring, and as one of the great methodological challenges for our community in the years to come (Besbeas et al., 2002).

Methodological progress in population dynamics is apparently still on an upward trajectory and we look forward to many exciting contributions at future EURING conferences!

\section{References}

Anderson, D. R., 2001. Euring 2000 conference. Euring Newsletter 3, July 2001. www.euring.org/about_euring/newsletter3/anderson.htm

Anderson, D. R. \& Burnham, K. P., 1976. Population ecology of the Mallard. VI the effect of exploitation on survival. US DI, Fish and WIldlife Service, Washington D.C.

Besbeas, P., Freema, S. N., Morgan, B. J. T. \& Catchpole, E. A., 2002. Integrating mark-recapture-recovery and census data to estimate animal abundance and demographic parameters. Biometrics, 58: 540-547.

Bonner, S. J. \& Schwarz, C. J., 2004. Continuous time-dependent Individual covariates and the CormackJolly-Seber model. Animal Biodiversity and Conservation, 27.1: 149-155.

- (in revision). An extension of the Cormack-Jolly-Seber model for continuous covariates with application to Microtus pennsylvanicus. Biometrics.

Boulinier, T., Nichols, J. D., Sauer, J. R., Hines, J. E. \& Pollock, K. H., 1998. Estimating species richness: the importance of heterogeneity in species detectability. Ecology, 79: 1018-1028.

Carothers, A. D., 1973. The effect of unequal catchability on Jolly-Seber estimates. Biometrics, 29(1): 79-100.

- 1979. Quantifying unequal catchability and its effects on survival estimates in an actual population. Journal of Animal Ecology, 48: 863-869.

Ferson, S. \& Burgman, M. (Eds.), 2000. Quantitative methods for conservation biology. Springer, New York. Gaston, K. J. \& Blackburn T. M., 2000. Pattern and process in macroecology. Blackwell Science, Oxford. Lebreton, J. D. (in press). The dynamics of exploited populations. Australian and New-Zealand journal of Statistics.

Lebreton, J. D. \& Pradel, R., 2002. Multistate recapture models: modeling incomplete individual histories. Journal of Applied Statistics, 29: 353-369.

Otis, D. L. \& White, G. C., 2004. Evaluation of ultrastructure and random effects band recovery models for estimating relationships between survival and harvest rates in exploited populations. Animal Biodiversity and Conservation, 27.1: 157-173.

Pledger, S., Pollock, K. H. \& Norris, J. L., 2003. Open capture-recapture models with heterogeneity. I. Cormack-Jolly-Seber model. Biometrics, 59: 786-794.

Pledger, S. \& Schwarz, C. J., 2002. Modelling heterogeneity of survival in band-recovery data using mixtures. Journal of Applied Statistics, 29: 315-327.

Pollock, K. H., Hines, J. E. \& Nichols, J. D., 1985. Goodness-of-fit tests for open capture-recapture models. Biometrics, 41: 399-410.

Pradel, R. (in press). Multievent models. Biometrics.

Pradel, R., Gimenez, O. \& Lebreton, J.-D. (in prep.). Principles and interest of GOF tests for multistate models.

Pradel, R., Wintrebert, C. \& Gimenez, O., 2003. A proposal for a goodness-of-fit test to the ArnasonSchwarz multisite capture-recapture model. Biometrics, 59: 43-53.

Seber, G. A., 1982. The estimation of animal abundance and related parameters. Griffin, London.

Sharpe, F. R. \& Lotka, A. J., 1911. A problem in Age-distribution. Philosophical magazine, series 6 21: 435-438. 